Original Article

\title{
ANTIOXIDANT AND HEPATOPROTECTIVE EFFECT OF QUERCUS ILEX LEAVES EXTRACT IN ETHANOL INDUCED LIVER DAMAGE IN WISTAR RATS
}

\author{
RENU MALIK ${ }^{1 *}$, K. G. SINGHAL ${ }^{2}$ \\ ${ }^{1}$ Lord Shiva College of Pharmacy, Sirsa, Haryana, India, ${ }^{2}$ ASBASJSM College of Pharmacy, Bela, Ropar, Punjab, India \\ Email: renumalik2912@gmail.com
}

Received: 22 Dec 2019, Revised and Accepted: 06 Feb 2020

\section{ABSTRACT}

Objective: This study was undertaken to investigate the hepatoprotective and antioxidant activity of Quercus ilex leaves extract (QILE) on ethanolinduced toxicity in Wistar rats.

Methods: Hepatotoxicity was induced by administering ethanol (40\%) at a dose of $7.9 \mathrm{gm} / \mathrm{kg} / \mathrm{day}$; p. o. (1:1 of ethanol in olive oil) for $28 \mathrm{~d}$. Silymarin $100 \mathrm{mg} / \mathrm{kg} /$ day; $p$. $o$. was used as a standard drug. The whole study was divided into a prophylactic and curative study. In the prophylactic study, the Silymarin and QILE (test drug) 100, 200, and $400 \mathrm{mg} / \mathrm{kg}$ Body Weight(BW) given orally one hour before administration of $40 \%$ ethanol administration for $28 \mathrm{~d}$. In the curative study, $7 \mathrm{~d}$ of treatment of Silymarin and QILE 200 and $400 \mathrm{mg} / \mathrm{kg}$ BW was given orally after 28 $\mathrm{d}$ of ethanol administration to different groups.

Results: Hepatoprotectivity was confirmed by the highly significantly $(p<0.001)$ restoration of elevated biochemical parameters like SGPT, SGOT, ALP, TB, and highly significantly $(p<0.001)$ depleted Albumin and Total protein levels by $200 \mathrm{mg} / \mathrm{kg}$ BW QILE in comparison to the positive control group. QILE $200 \mathrm{mg} / \mathrm{kg}$ highly significantly $(p<0.001)$ raised the antioxidants by draining the elevated oxidative stress markers in comparison of positive control group. At dose levels QILE $200 \mathrm{mg} / \mathrm{kg}$, significant $(p<0.05)$ protection from loss in body weight and in liver weight was found when the comparison was done with the positive control group. Histopathology revealed that QILE $200 \mathrm{mg} / \mathrm{kg}$ reduced the markers of cell necrosis.

Conclusion: Present study revealed that Quercus ilex leaves have antioxidant and hepatoprotective activity due to its chemical constituents.

Keywords: Hepatotoxicity, Ethanol, Silymarin, Quercus ilex, Antioxidant

(C) 2020 The Authors. Published by Innovare Academic Sciences Pvt Ltd. This is an open access article under the CC BY license (http://creativecommons.org/licenses/by/4.0/) DOI: http://dx.doi.org/10.22159/ijpps.2020v12i4.36689. Journal homepage: https://innovareacademics.in/journals/index.php/ijpps

\section{INTRODUCTION}

"The preservation of health is easier than the cure of disease," the famous words of BJ Palmer, Developer of Chiropractic. Health preservation is done by including lots of useful herbs in our meal. The presence of a huge variety of herbs in nature shifted the focus of scientist to herbal therapeutic interventions instead of chemical components which are prone toward hazardous effects. Hepatic diseases have become one of the major causes of morbidity and mortality due to alcohol abuse over the counter drugs other toxicants. All these make the liver vulnerable to a variety of disorders such as hepatitis, cirrhosis and jaundice [1]

In India, Quercus ilex (Family: Fagaceae, Common name-Holly oak, Holm oak) is distributed in inner arid tracts of Himalayas from Satluj valley westward and in Kashmir and Himachal Pradesh, Manipal, at the attitude of 900-2600 meters [2] and along the Balkan Peninsula, North Spain and West France [3].

Quercus ilex is one of the most commonly used plants in Morocco to treat gastrointestinal disorders and skin infections [4]. The bark of Quercus ilex is used in decoction or as a powder, alone or mixed with Punicagranatum and Ceratonia silica to treat stomachache [5]. It is also used to treat throat infection, hemorrhages, and dysentery. It is reported that the Ethyl acetate, butanol and aqueous extracts [6] and methanol extracts of Quercus ilex leaves from Turkey [7] possess antibacterial activity. Quercus ilex leaves are a rich source of polyacylated flavonoids [8].

It is traditionally used as Anti-inflammatory „, Cirrhosis, Conjunctivitis, Enterocolitis, Gastroenterosis, Gout, Hepatosis, Immunodepression, Psoriasis, Rheumatism, Splenosis, Uterosis, Tonsilosis, Nephrosis, Enterosis, Breast Cancer, Colon Cancer, Intestine Cancer, Liver cancer, Kidney Stone, Cold cough, Dysentery, Vaginosis [9].

With the presence of chemical constituents and traditional background, the present study was carried out to investigate antioxidant and hepatoprotective activity of ethanol extract of Quercus ilex leaves by assaying various antioxidant enzymes and serum marker enzymes in ethanol intoxicated female rats.

\section{MATERIALS AND METHODS}

\section{Plant material and extract preparation}

The leaves of Quercus ilex were collected from the Kinnor district of Himachal Pradesh in India and authenticated by Himalayan Forest Research Institute, Conifer Campus, Panthaghati, Shimla (authentication No. DD27014) dated $16 / 8 / 12$ by Dr. Vaneet Jishtu. The leaves of Quercus ilex dried in the shade and coarsely powdered. The defatting of leaves was done by a Soxhlet apparatus with petroleum ether. Then extraction of defatted powdered leaves was done by using 95\% ethanol. The extract was drying in Rota Evaporator at $45^{\circ} \mathrm{C}$. The dried extract stored in the Vaccum desiccator during the study.

\section{Drug and chemicals}

Silymarin received as a gift from Ranbaxy Laboratories, Delhi, India. Thiobarbituric acid (TBA), 5, 5'-dithiobis (2-nitrobenzoic acid)(DTNB), DPPH purchased from Himedia Laboratories, Mumbai, India. Malondialdehyde (MDA) obtained from Sigma Chemicals Company, St Louis, MO, USA. All other chemicals and reagents were purchased commercially by local vendors and were of analytical grade.

\section{Preparation of test and standard drug}

Ethanol $(7.9 \mathrm{~g} / \mathrm{kg} /$ day $)$ was diluted up to $40 \%$, making a solution of $1: 1$ of ethanol in olive oil [10]. The test drug dissolved in lukewarm water. Silymarin $100 \mathrm{mg} / \mathrm{kg} /$ day; $p$. $o$. was administered as a suspension in a $1 \%$ aqueous solution of carboxymethyl cellulose.

\section{Acute oral toxicity study}

Acute toxicity is involved in the estimation of LD50 (the dose which has proved to be lethal to $50 \%$ of the tested group of animals). 
Female Wistar rats $(n=3)$ were randomly selected and kept fasting overnight [11]. The crude ethanol extract of quercus ilex leaves was administered to the different rats in doses of 500, 1000 and 3000 $\mathrm{mg} / \mathrm{kg} \mathrm{BW}$, respectively. The rats were observed for physiological changes due to toxicity such as weakness, feed withdrawal, dizziness, vomiting, and mortality for $14 \mathrm{~d}$.

\section{Experimental animals}

Adult female Wistar rats (180-200, 6 wks) purchased from CPCSEA approved registered breeder. The animals brought to animal house to acclimatize in new environment for $7 \mathrm{~d}$ before start of experiments and housed under standard laboratory conditions with $23 \pm 1{ }^{\circ} \mathrm{C}$ temperature, $55 \pm 10 \%$ relative humidity, $12 / 12 \mathrm{~h}$ light/dark cycles, in propylene cages, and fed with standard pellet diet from Ashirwad Industry and purified water ad libitum [10]. The experimental protocol was approved for hepatoprotective activity by the Institution Animal Ethics Committee (Reg No. 724/P0/a/02/CPCSEA) with protocol No ASCB/IAEC/05/12/071 on dated.

\section{Experimental procedure}

After acclimatization of 6-7 d, animals were randomly divided into 9 groups of six each. A total of 54 rats was divided into nine groups of 6 rats each. The study was performed in two phases that are the prophylactic phase and the curative phase.

- $\quad$ Group 1 received only the saline ( $1 \mathrm{ml} / \mathrm{kg} /$ day; p. o.) served as the control group.

- $\quad$ Group 2 received $40 \%$ ethanol $7.9 \mathrm{~g} / \mathrm{kg} /$ day (1:1 of ethanol in olive oil) [10] orally for $28 \mathrm{~d}$ and served as the positive control group.

\section{Prophylactic study}

- $\quad$ Group 3 received silymarin $100 \mathrm{mg} / \mathrm{kg}$ orally one hour before $40 \%$ ethanol administration $7.9 \mathrm{~g} / \mathrm{kg} /$ day (1:1 of ethanol in olive oil) for $28 \mathrm{~d}$.

- $\quad$ Groups 4th, 5th, 6th were administered QILE 100, 200, and 400 $\mathrm{mg} / \mathrm{kg}$ BW orally (decided as per acute oral toxicity study) respectively one hour before administration of $40 \%$ ethanol administration $7.9 \mathrm{~g} / \mathrm{kg} /$ day (1:1 of ethanol in olive oil) for $28 \mathrm{~d}$.

\section{Curative study}

- $\quad$ Group 7 received silymarin $100 \mathrm{mg} / \mathrm{kg}$ orally for 7 days after 28 $\mathrm{d}$ of ethanol administration.

- $\quad$ Groups 8th, 9th were received seven days of treatment of QILE 200 and $400 \mathrm{mg} / \mathrm{kg} \mathrm{BW}$ orally, respectively, after $28 \mathrm{~d}$ of ethanol administration.

All rats were sacrificed by cervical dislocation after $24 \mathrm{~h}$ of the last treatment. Blood was collected before sacrifice, under mild chloroform anesthesia from the retro-orbital sinus plexus. The serum was separated from collected blood at $3000 \mathrm{rpm}$ for $15 \mathrm{~min}$ and used for the determination of marker enzymes (AST, ALP, ALT), albumin, total protein, total bilirubin.

The livers were dissected immediately, washed with ice-cold saline, and divided into two equal parts. One part was used for histopathological study after fixed in $10 \%(\mathrm{w} / \mathrm{v})$ buffered formalin, and other for the assays of antioxidant enzymes GSH, CAT, and lipid peroxidation.

\section{Marker enzyme assays}

The liver marker enzymes AST, ALT, and ALP were assayed in serum by IFCC method using standard kits supplied from Span Diagnostics (Surat, India). The results were expressed as IU/l.

\section{Protein determination}

The levels of TP and Alb were determined in the serum of experimental animals by using the Lowry method and the bromocresol green method, respectively [12]. Kits purchased from Span Diagnostics (Surat, India) for Alb assay.

\section{Total Bilirubin estimation}

Total Bilirubin was estimated by measuring the absorbance of colored azobilirubin at $546 \mathrm{~nm}$ and directly proportional to the total bilirubin concentration in the sample [13].

\section{Lipid peroxidation and antioxidant enzyme activity}

The rats were sacrificed, and their livers excised, rinsed in ice-cold normal saline followed by $0.15 \mathrm{M}$ Tris- $\mathrm{HCl}(\mathrm{pH} 7.4)$ blotted dry and weighed. The estimation of lipid peroxidation by the method of Ohkawa [14] after preparation of $10 \% \mathrm{w} / \mathrm{v}$ of homogenate prepared in $0.15 \mathrm{M}$ Tris-HCl buffer. A part of homogenate was used for the estimation of glutathione by the method of Ellman [15] after precipitating proteins. The rest of the homogenate was centrifuged at $4{ }^{\circ} \mathrm{C}$ for $15 \mathrm{~min}$ at $15000 \mathrm{rpm}$. The supernatant thus obtained was used for the estimation of CAT activities was measured by the method of Aebi [16].

\section{Histopathology}

The isolated livers were fixed in a $10 \%$ formalin solution and dehydrated by using ethanol. Dehydrated liver pieces were embedded in paraffin to become hard. Solid liver pieces were sectioned with a thickness of 5-6 $\mu \mathrm{m}$ and then stained with eosin and hematoxylin. These sections examined for histoarchitectural changes under a light microscope [17].

\section{Statistical analysis}

The data were expressed as mean \pm SEM. Statistical differences at $p<0.05$ between the groups were analyzed by one-way ANOVA followed by Turkey's multiple comparison tests using Graph Pad Prism software package.

\section{RESULTS}

\section{Yield value of the extract}

The $17.2 \%$ total yield of Quercus ilex leaves extract. Dried extract stored in vacuum desiccators containing anhydrous silica gel.

\section{Acute oral toxicity study of QILE}

Determine the maximum safe dose of QILE by acute oral toxicity studies in rats at $2000 \mathrm{mg} / \mathrm{kg}$, followed by OECD guidelines. On the bases of observations, it is evident that there is no reduction in alertness, spontaneous motor activity, reactivity to sound and touch, body, and limb tone. Respiration, urination, pupil size, reflexes (pineal, corneal, righting) were found normal for all $14 \mathrm{~d}$ of study.

Table 1: Animal weight (g) with the time of treatment

\begin{tabular}{lll}
\hline Group & Initial body wt. (g) & Final body wt. (g) \\
\hline Control & $249.5 \pm 3.40$ & $268.0 \pm 3.89^{\mathrm{b}}(\uparrow)$ \\
Positive control & $255.7 \pm 7.61$ & $236.8 \pm 10.66^{\beta}(\downarrow)$ \\
Silymarin (Prophylactic) & $253.2 \pm 4.75$ & $258.5 \pm 4.37^{\mathrm{a}}(\uparrow)$ \\
QILE 100 (Prophylactic) & $268.8 \pm 6.80^{\alpha}$ & $260.7 \pm 6.01(\downarrow)$ \\
QILE 200 (Prophylactic) & $250.2 \pm 3.91$ & $253.2 \pm 4.19(\uparrow)$ \\
QILE 400 (Prophylactic) & $254.7 \pm 4.01$ & $255.5 \pm 4.93(\uparrow)$ \\
Silymarin (Curative) & $253.8 \pm 6.34$ & $256.5 \pm 6.35^{\mathrm{a}}(\uparrow)$ \\
QILE 200 (Curative) & $250.8 \pm 2.50$ & $252.5 \pm 1.87(\uparrow)$ \\
QILE 400 (Curative) & $247.2 \pm 8.55^{\alpha}$ & $248.0 \pm 8.09(\uparrow)$ \\
\hline
\end{tabular}

Value mean \pm SEM, $(\mathrm{n}=6)$ symbols represent statistical significance. ${ }^{\alpha} \mathrm{p}<0.05,{ }^{\beta} \mathrm{p}<0.01$ Vs Control, ${ }^{\mathrm{a}} \mathrm{p}<0.05,{ }^{\mathrm{b}} \mathrm{p}<0.01$ Vs Positive Control One way ANOVA followed by Tukey's Multiple Comparison test. 


\section{Bodyweight}

One does not notice a significant difference between the weights of the animals of the positive control group and the test group ( $p>0.05)$ from the first day of the treatment. However, there should have been an increment in the weight of the animal as per the processing time expressed in the week. But in positive control group animals, a decrease in weight was observed after four weeks in comparison to control group animals. Treatment with QILE restored the weight loss in animals in comparison to the control group. At dose levels QILE 200 and $400 \mathrm{mg} / \mathrm{kg}$, significant protection from loss in body weight in both curative and prophylactic treatments. The results are consigned through table 1.

\section{Liver weight}

A highly significantly $(p<0.001)$ increase in liver weight of ethanol intoxicated positive control group animals than in normal salinetreated control group (table 2).

Prophylactic treatment of $28 \mathrm{~d}$ with silymarin and QILE 200 restored the inclined level of liver weight highly significantly when a comparison was done with the intoxicated positive control group and highly significantly than the saline-treated control group. When the curative study was done for seven days, silymarin, QILE 200, and QILE 400 showed non-significant $(p<0.05)$ and $(p<0.01)$ results when compared with a saline-treated control group and highly significantly than the intoxicated positive control group.

Table 2: Animal liver weight (g) with the time of treatment

\begin{tabular}{lc}
\hline Groups & Liver wt./100g \\
\hline Control & $2.94 \pm 0.06^{\mathrm{c}}$ \\
Positive control & $4.04 \pm 0.09^{\gamma_{z}}$ \\
Silymarin (Prophylactic) & $3.14 \pm 0.03^{\mathrm{c}}$ \\
QILE 100 (Prophylactic) & $3.70 \pm 0.04^{\gamma_{\mathrm{zaz}}}$ \\
QILE 200 (Prophylactic) & $3.22 \pm 0.02^{\mathrm{c}}$ \\
QILE 400 (Prophylactic) & $3.27 \pm 0.06^{\alpha \mathrm{c}}$ \\
Silymarin (Curative) & $3.21 \pm 0.02^{\mathrm{c}}$ \\
QILE 200 (Curative) & $3.28 \pm 0.08^{\alpha \mathrm{c}}$ \\
QILE 400 (Curative) & $3.34 \pm 0.08^{\beta c}$ \\
\hline
\end{tabular}

Value mean \pm SEM, $(\mathrm{n}=6)$ symbols represent statistical significance. ${ }^{\alpha} p<0.05,{ }^{\beta} p<0.01$ and ${ }^{\gamma} p<0.001$ Vs Control, ${ }^{a} p<0.05,{ }^{b} p<0.01$ and ${ }^{c} p<0.001$ Vs Positive Control, ${ }^{x} p<0.05, y p<0.01$ and ${ }^{z} p<0.001$ Vs Standard Silymarin. One way ANOVA followed by Tukey's multiple comparison test.

\section{Effect on serum biochemical parameters}

The impact of QILE on serum marker enzymes SGOT, SGPT, ALP, Albumin, Total Protein, and Total bilirubin (TB) summarized in table 3. A significant $(p<0.001)$ elevation in serum SGOT, SGPT, ALP, and TB observed in animals intoxicated with ethanol i.e., positive control group (PC) when compared with normal saline-treated animals group i.e., control group. During $28 \mathrm{~d}$ prophylactic treatment, serum level of SGOT, SGPT, ALP, and TB were highly significantly $(p<0.001)$ decreased in silymarin and three selected dose levels of QILE (100, 200 and $400 \mathrm{mg} / \mathrm{kg}$ ) treated groups when compared to the positive control group. When the results of the above serum enzymes level were compared to normal saline-treated group, effects of silymarin and QILE $200 \mathrm{mg} / \mathrm{kg}$ were non-significant, QILE $100 \mathrm{mg} / \mathrm{kg}$ highly significantly $(p<0.001)$ and QILE $400 \mathrm{mg} / \mathrm{kg}$ significantly $(p<0.05)$. After $28 \mathrm{~d}$ of intoxication with ethanol, seven days curative treatment of silymarin, QILE 200, and $400 \mathrm{mg} / \mathrm{kg}$ showed a highly significant $(p<0.001)$ decline in serum level of SGOT, SGPT, ALP and TB in comparison to intoxicated animals. Silymarin, QILE 200 and $400 \mathrm{mg} / \mathrm{kg}$ revealed a non-significant, significant $(p<0.05)$ and $(p<0.01)$, respectively, when the comparison was made with the control group.

TP and albumin levels in serum decline highly significantly $(p<0.001)$ in ethanol intoxicated positive control group animals in comparison to normal saline-treated control group animals. In prophylactic treatment, Silymarin, QILE significantly decrease the elevated levels of serum TP, and albumin content in ethanol intoxicated positive control group animals when the comparison was made with positive control group animals. QILE 100 and 400 $\mathrm{mg} / \mathrm{kg}$ dose levels restored highly significantly $(p<0.001)$ and $(p<0.05)$, respectively the elevated level of serum TP and albumin content while Silymarin and QILE $200 \mathrm{mg} / \mathrm{kg}$ showed nonsignificant result when the comparison was done with the normal saline-treated control group. During curative treatment, silymarin and QILE (200 and $400 \mathrm{mg} / \mathrm{kg}$ ) revealed a significant elevation in serum TP and albumin content when the comparison was done with positive control group animals and showed a non-significant, $(p<0.05)$ and $(p<0.01)$ respectively compared with control group animals.

Table 3: Hepatoprotective evaluation of QILE on serum parameters

\begin{tabular}{|c|c|c|c|c|c|c|}
\hline Groups & SGPT/AST & SGOT/ALT & ALP & Total Protein & Albumin & T. B. \\
\hline Control group & $146.7 \pm 3.85^{c}$ & $59.43 \pm 2.19^{c}$ & $178.6 \pm 4.05^{\mathrm{c}}$ & $9.66 \pm 0.18^{\mathrm{c}}$ & $6.12 \pm 0.07 \mathrm{c}$ & $0.39 \pm 0.02^{\mathrm{c}}$ \\
\hline Positive control & $248.2 \pm 4.14^{\gamma_{z}}$ & $108.6 \pm 3.04^{\gamma_{z}}$ & $319.8 \pm 3.10^{\gamma_{z}}$ & $3.93 \pm 0.11^{\gamma_{z}}$ & $3.35 \pm 0.09^{\gamma_{z}}$ & $4.1 \pm 0.04^{\gamma_{z}}$ \\
\hline \multicolumn{7}{|l|}{ Prophylactic study } \\
\hline Silymarin+Alcohol & $152.9 \pm 5.46^{c}$ & $62.42 \pm 3.54^{c}$ & $189.7 \pm 3.74^{c}$ & $9.34 \pm 0.22^{\mathrm{c}}$ & $5.92 \pm 0.12^{\mathrm{c}}$ & $0.46 \pm 0.02^{\mathrm{c}}$ \\
\hline QILE 100+Alcohol & $179.4 \pm 1.89^{\gamma_{\mathrm{cz}}}$ & $82.83 \pm 1.71^{\gamma_{c z}}$ & $230.3 \pm 4.30^{\gamma_{c z}}$ & $7.73 \pm 0.16^{\gamma_{c z}}$ & $4.60 \pm 0.08^{\gamma_{c z}}$ & $1.89 \pm 0.06 \gamma_{\mathrm{cz}}$ \\
\hline QILE 200+Alcohol & $158.7 \pm 2.98^{c}$ & $66.25 \pm 2.88^{\mathrm{c}}$ & $192.9 \pm 3.79^{c}$ & $9.07 \pm 0.06^{c}$ & $5.64 \pm 0.14 \mathrm{c}$ & $0.53 \pm 0.01^{\mathrm{c}}$ \\
\hline QILE 400+Alcohol & $163.4 \pm 1.83^{\alpha c}$ & $72.25 \pm 0.81^{\alpha c}$ & $196.5 \pm 4.40^{\alpha c}$ & $8.91 \pm 0.04^{\alpha c}$ & $5.49 \pm 0.14 \beta c$ & $0.59 \pm 0.01^{\beta c}$ \\
\hline \multicolumn{7}{|l|}{ Curative study } \\
\hline Silymarin+Alcohol & $157.01 \pm 2.05^{\mathrm{c}}$ & $68.05 \pm 1.55^{\mathrm{c}}$ & $190.0 \pm 5.05^{\mathrm{c}}$ & $9.2 \pm 0.14^{\mathrm{c}}$ & $5.7 \pm 0.11^{\mathrm{c}}$ & $0.48 \pm 0.01^{\mathrm{c}}$ \\
\hline QILE 200+Alcohol & $160.3 \pm 1.87 \alpha c$ & $69.84 \pm 1.46^{\alpha c}$ & $199.1 \pm 2.21^{\alpha c}$ & $8.98 \pm 0.05^{\alpha c}$ & $5.46 \pm 0.11^{\alpha c}$ & $0.54 \pm 0.02^{\beta c}$ \\
\hline QILE 400+Alcohol & $164.5 \pm 1.31^{\beta c}$ & $70.75 \pm 1.81^{\beta c}$ & $203.30 \pm 2.04^{\beta c}$ & $8.77 \pm 0.16^{\beta c}$ & $5.34 \pm 0.24 \beta c$ & $0.69 \pm 0.02^{\gamma_{c z}}$ \\
\hline
\end{tabular}

Value mean \pm SEM, $(\mathrm{n}=6)$ symbols represent statistical significance. ${ }^{\alpha} P<0.05, \beta P<0.01$ and ${ }^{\gamma} P<0.001$ Vs Control, ${ }^{\gamma} P<0.001$ Vs Positive Control, ${ }^{z} P<0.001$ Vs Standard Silymarin. One way ANOVA followed by Tukey's Multiple Comparison test. SGPT/AST-Serum Glutamate Pyruvic Transaminase/Aspartate Transaminase, SGOT/ALT-Serum Glutamate Oxaloacetate Transaminase/Alanine Transaminase, ALP-Alkaline Phosphatase, T. B.-Total bilirubin

\section{Histopathological studies}

The liver of animals of the control group showed normal histology. The liver section of the intoxicated ethanol group showed a marked degree of fatty changes. A high degree of infiltration of inflammatory cells, especially neutrophils, was seen within all zones. Inclusion in cytoplasm (Mallory bodies) formation also observed at a high level. Many hepatocytes showed degenerative changes. Compared with 
the fatty changes observed in intoxicated ethanol animals, fat deposition in the silymarin treated group was much milder degree. Mild stromal inflammatory infiltration comprising neutrophils, lymphocytes, and macrophages were also seen within the periportal and focal midzone area. Regeneration of cells was observed in the silymarin group. The livers in the QILE 100 group showed a moderate degree of inflammatory cell infiltration within all zones leads to mild fatty changes and regeneration of few cells. QILE 200 $\mathrm{mg} / \mathrm{kg}$ slight degree of inflammatory cell infiltrations within all zones, and many regenerative cells also noticed. Histo-architecture of QILE 200 treated rats tended to be more usual compared to QILE 400, while silymarin treated rats showed almost normal histology.

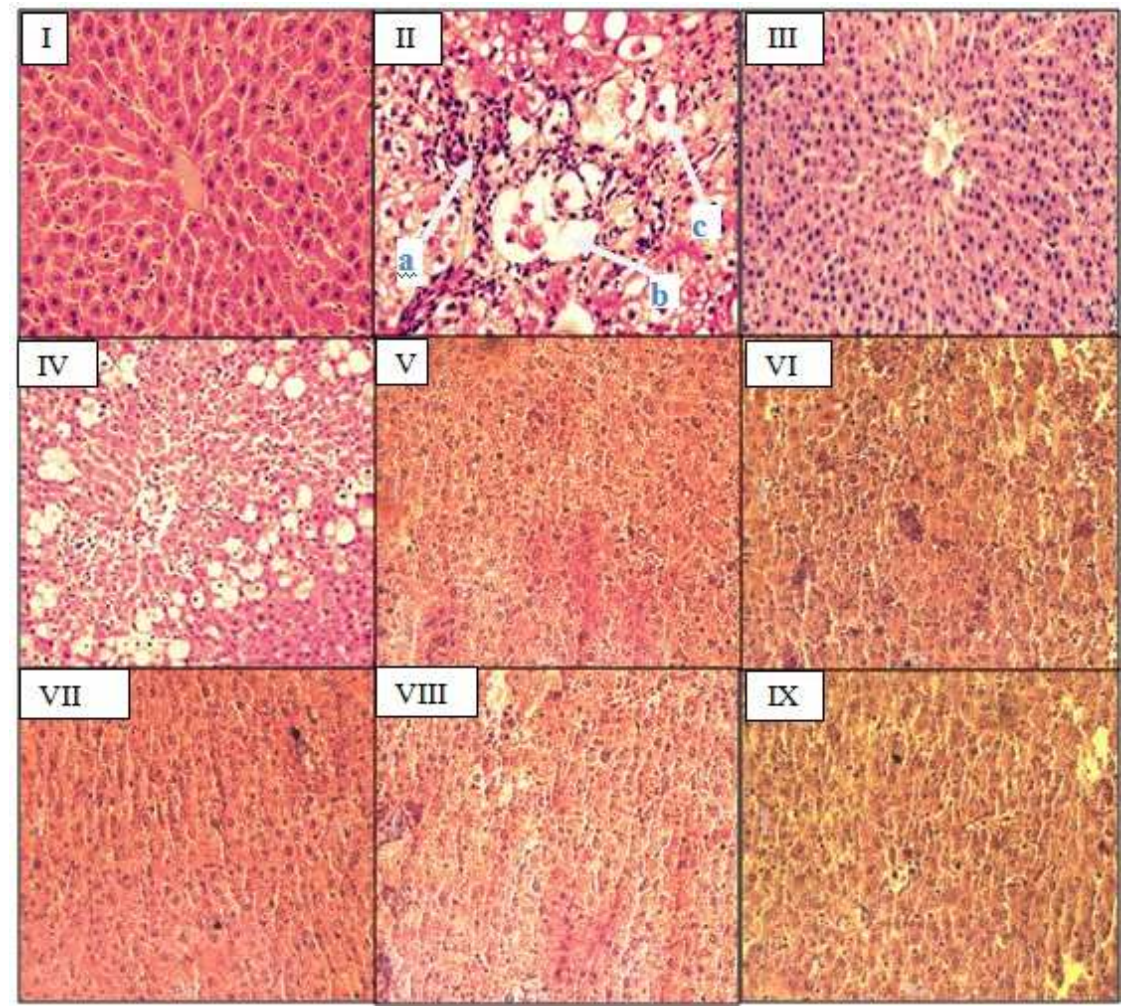

Fig. 1: Representative photomicrographs of liver sections, Group I: Liver section of normal rats showing central vein surrounded by hepatic cord of cells (normal architecture). Group II: liver section of alcohol treated rats showing massive fatty changes (b), mallory body formation (c), infilteration of neutrophils (a), prolifration of Kupffer cells. Group III: In silymarin treated group liver section showing regenerative changes in hepatocytes and minimal inflammatory changes. Group IV: In QILE $100 \mathrm{mg} / \mathrm{kg}$ treated group, liver section showing marked fatty changes, ballooning degeneration, infilteration if inflammatory cells around central vein. Group V: In QILE 200 $\mathrm{mg} / \mathrm{kg}$ treated group, liver section showing mild fatty changes and regeneration of hepatocytes. Group VI: In QILE $400 \mathrm{mg} / \mathrm{kg}$ treated group, modrate fatty changes, infilteration of inflammatory cells. Group VII: In silymarin $100 \mathrm{mg} / \mathrm{kg}$ curative group, liver section showing regenerative changes in hepatocytes and minimal inflammatory change. Group VIII: In QILE $200 \mathrm{mg} / \mathrm{kg}$ curative group, liver section showing mild fatty changes and regeneration of hepatocytes. Group IX: In QILE $400 \mathrm{mg} / \mathrm{kg}$ curative group, liver section showing modrate fatty changes and regeneration of hepatocytes

\section{DISCUSSION}

The liver plays a significant role in the metabolism of various nutrients, detoxification of many endogenous and exogenous compounds. There are many xenobiotics and toxicants which affect liver functions and damage. Ethanol is one of the liver toxicants, which can damage the liver on chronic use. $80 \%$ of ethanol is metabolized by the liver via various metabolic pathways. Management of ethanolic liver diseases is still a challenge to modern medicine. Conventional drugs used in the treatment of ethanolic liver diseases are often inadequate. Natural plant products have been the main source of treatment for many ailment including liver diseases for centuries, with about $80 \%$ of the population in poor resource areas currently depending on traditional medicine for their primary health care [18].

Ethanol is metabolized by the gastric ethanol dehydrogenase and converts into acetaldehyde. Aldehyde oxidase or xanthine oxidase oxidizes acetaldehyde to acetate by via cytochrome P450 2E1, catalase [19]. Ethanol gives rise to the state of oxidative stress by depleting the various antioxidant enzymes. Besides, ethanol also decreases ATP production by damaging the mitochondria $[20,21]$. Ethanol induces oxygen deficiency by utilizing more oxygen in its metabolism, which amplifies the ROS production and prone the hepatocytes toward lipid peroxidation. Ethanol consumption increases the level of gut-derived endotoxin to the portal circulation. In response to endotoxins, kupffer cells are activated. Activated kupffer cells enhance the secretion of proinflammatory cytokines and suppress anti-inflammatory cytokine secretion. This results inflammation of hepatocytes and causes cell damage [22].

The acute oral toxicity study revealed that the absence of lethality among the tested animals when administration of QILE as a single dose $(2000 \mathrm{mg} / \mathrm{kg})$. There was no sign of any gross changes except sedation for one to two hr indicating the safe use of the extract.

Present study explored the in vivo antioxidant and hepatoprotective of Quercus ilex leaves extract in both prophylactic and curative condition. QILE was administered with olive oil (1:1). It has been reported that high fat ethanol diet provokes the development of liver lesions. With this model, sustained high ethanol levels were obtained and progressive stetosis was accampained by the development of foccal inflammation and necrosis [23], especially when a diet rich in polyunsaturated fatty acids was used [24,11],

All selected dose levels showed a significant hepatoprotection by preventing the elevation of transaminase, alkaline phosphatase, and 
bilirubin levels as compared to intoxicated ethanol animals. These are the potent biomarkers of hepatotoxicity. Ethanol treatment causes cell necrosis in the liver, leakage of all these enzymes in the blood [25]. Decreased the level of total protein and albumin content in QILE treated animals reflects the hepatoprotective activity of extract as compared to ethanol-treated animals. The elevation in the total protein (TP) and albumin is demonstrating the initial damage produced in ethanol-treated animals due to leakage of nitrogenous substances (non-protein and protein) on destruction of cells; this leads to impairment in protein synthesis and it transamination [26].

The current study indicates that ethanol exaggerates lipid peroxidation. The increase in the MDA level in ethanol-treated liver exhibits enhanced peroxidation leading to tissue damage and failure of antioxidant mechanisms to prevent the formation of excessive free radicals [27]. Oral administration of QILE significantly reverses these changes, suggesting a protective effect.

QILE treatment also demonstrated its antioxidant activity by relieving the cell from oxidative stress by decreasing the lipid peroxidation insult and maintains the glutathione level, catalase activity, indicating the protection of hepatocytic cell membrane structural integrity or damaged liver cells regeneration. Glutathione and catalase are the first line of cellular defense enzymes and act as free radical scavenging enzymes. These enzymes dispose of $\mathrm{O}_{2}$ and $\mathrm{H}_{2} \mathrm{O}_{2}$ before their interaction to form the more harmful hydroxyl $\left(\mathrm{OH}^{\circ}\right)$ radical [28]. Reduced glutathione is one of the most abundant non-enzymatic antioxidant bio-molecules present in tissues [29]. QILE treatment revealed a significant increase in catalase activity and glutathione levels in rats as compared to intoxicated rats (table 4).

Concerning the effect of the extracts on the body weight of the rats, the results consigned in table 1 . There is a relation between the outcome of the extracts, the bodyweight of the rats, and the duration of the treatment. Studies reported that weight is a significant and straightforward index of toxicity after exposure to toxic substances. Statistical studies revealed that there is a weak significant difference in the profit of body weight in a group of ethanol-treated animals for four weeks as compared to control group animals. The result also indicates an increase in animal weight according to the treatment period. The lesser gain in body weight seen in ethanol-treated animals, affects food utilization or increase in calories loss. The reduction in the weight in the rat is the direct result of the signs of affection of the liver caused by ethanol [30].

Our study revealed that the weight of the liver significantly increases in ethanol-treated animals as compared to the control group. QILE treatment substantially prevents the elevation in liver weight in ethanol animals (table 2). Ethanol intake exhibits the fat accumulation in the liver by increase the hepatic production of fatty acid, triglyceride, and decreases hepatic fatty acid oxidation leads to fatty liver. In fatty liver, impaired filtration of neutrophils and lipoprotein [30] enhances the liver volume. QILE treatment prevents an increase in liver weight by inhibiting fat deposition in the liver.

We carried out prophylactic and curative treatment of QILE on intoxicated ethanol animals. Our data revealed that QILE $200 \mathrm{mg} / \mathrm{kg}$ dose showed more antioxidant and hepatoprotective effects in comparison to QILE 100 and $400 \mathrm{mg} / \mathrm{kg}$. Twenty-eight days of prophylactic treatment is more effective than seven days of curative treatment.

Histopathological study revealed that QILE treatment decreases the fat deposition; prevent Mallory body formation, neutrophils infiltrations in liver cells as compared to ethanol-treated animals (fig. 1).

Phytoconstituents like the flavonoids, triterpenoids, and glycosides [31] are confirmed in Quercus ilex. Phytochemical screening revealed that ethanol extract of Quercus ilex leaves contains active pharmacological constituents such as flavonoids, alkaloids, triterpenoids, and phenolic compounds. However, it has already been reported that such phytoconstituents like phenolic compounds, flavonoids, tannins [32] are known to possess hepatoprotective activity in various experimental models. Kaempferol, ellagic acid, gallic acid, catechin, quercetin present in Quercus ilex leaves revealed antioxidant and hepatoprotective activity, which is being also confirmed by the biochemical and histological parameters.

\section{CONCLUSION}

Quercus ilex is an enriching plant in flavonoids, triterpenoids, glycosides, ascorbic acid. Due to all these constituents, it shows antioxidant activity. Our study revealed its antioxidant and hepatoprotective activity. From future aspects, due to its antioxidant activity, it can be used in various diseases like diabetes, inflammatory diseases, and neuronal disorders etc. causes oxidative stress. Further phytochemical study or isolation of principle active constituents from Quercus ilex may give rise to the evaluation of various pharmacological activities.

\section{ACKNOWLEDGMENT}

We thank Haryana Agriculture University, Hisar, Haryana, India, for providing animals for this study.

\section{FUNDING}

Nil

\section{AUTHORS CONTRIBUTIONS}

Research was done by corresponding author Renu Malik, under the guidance of Dr. K. G. Singhal.

\section{CONFLICTS OF INTERESTS}

The authors have no conflicts of interest

\section{REFERENCES}

1. Balne D, Pallerla P, Vanapatla S, Bobbala RK. Hepatoprotective effect of whole plant extract fractions of Marsilea minuta Linn. Asian J Pharm Clin Res 2013;6:100-7.

2. Vaidya Sala A. Indian medicinal plants: a compendium of 500 species. Vol.2: Universities Press; 2013. p. 576.

3. Tutin TG, Burges NA, Chater AO, Edmonson JR, Heywood VH, Moore DM. Flora Europaea. Vol. 1; 1991. p. 74.

4. Bellakhdar J. La pharmacop'ee marocaine traditionnelle. Ibis Press; 1997. p. 764.

5. Benchaabane A, Abbad A. Les plantes medicinales commercialiseesa Marrakech. Trace du Present, Marrakech; 1997. p. 74.

6. Berthoud A, Rahmani N, Fdil A, Benharref M, Jana CA. Antibacterial activity of Quercus ilex bark's extracts. J Ethnopharmacol 2007;112:426-9.

7. Gallucii M, Adiguzel A, Ogutcu H, Sengul M, Karaman I, Sahin F. Antimicrobial effects of Quercus ilex L. extract. Phytother Res 2004;18:208-11.

8. Karioti A, Bilia AR, Skaltsa H. Quercus ilex-A rich source of polyacylated flavonoids glucosides. Food Chem 2010;123:13142.

9. Luna RK. Plantation Trees. Dehradun: International book distributors; 1996. p. 993.

10. Nanji AA, Sadrzadeh SM, Yang EK, Fogt F, Meydani M, Dannenberg AJ. Dietary saturated fatty acids: a novel treatment for alcoholic liver disease. Gastroenterology 1995;109:547-54.

11. India: Ministry of Social Justice and Empowerment. Committee for the Purpose of Control and Supervision of Experimental Animals (CPCSEA), OECD Guidelines for the testing of chemicals, revised draft guidelines 423: Acute Oral toxicityAcute toxic class method, revised document; 2000.

12. Lowry OH, Rosebrough NJ, Farr AL, Randall RJ. Protein measurement with the folin phenol reagent. J Biol Chem 1951;193:265-75.

13. Malloy HJ, Evelyn KA. The determination of bilirubin with the photoelectric colorimeter. J Biol Chem 1937;119:481.

14. Ohkawa H, Onishi N, Yagi K. Assay for lipid peroxidation in animal tissue by the thiobarbituric acid reaction. Anal Biochem 1979;95:351-8.

15. Ellman GL. Tissue sulphydryl groups. Arch Biochem Biophys 1959;82:70-7.

16. Aebi H, Wyss SR, Scherz B, Skvaril F. Heterogeneity of erythrocyte catalase. II. Isolation and characterization of 
normal and variant erythrocyte catalase and their subunits. Eur J Biochem 1974;48:137-45.

17. Luna Lee G. Manual of histologic staining methods of the armed forces institute of pathology. $3^{\text {rd }}$ ed. Blakiston Divison: Mc-Graw Hill; 1968.

18. Kumar A, Pai MO, Rai N. In vitro hepatoprotective activity of Albizia lebbeck, Cassia occidentalis and Swertia chirata on HEPG2 cells. Asian J Pharm Clin Res 2016;9:276-80.

19. Tuma DJ, Casey CA. Dangerous byproducts of alcohol breakdown: focus on adducts. Alcohol Res Health 2003;27:285-90.

20. Thurman RG, Ji S, Matsumura T, Lemasters JJ. Is hypoxia involved in the mechanism of alcohol-induced liver injury? Fundam Appl Toxicol 1984a;4:125-33.

21. Thurman RG, Ji S, Lemasters JJ. Alcohol-induced liver injury. The role of oxygen. Recent Dev Alcohol 1984b;2:103-17.

22. Kono H, Arteel GE, Rusyn I. Ebselen prevents early alcohol-induced liver injury in rats. Free Radicals Biol Med 2001;30:403-11.

23. Tsukamoto H, French SW, Benson N, Delgado G, Rao GA, Larkin EC, et al. Severe and progressive steatosis and focal necrosis in rat liver induced by continuous intragastric infusion of ethanol and low fat diet. Hepatology 1985;5:224-32.

24. Nanji AA, Mendenhall CL, French SW. Beef fat prevents alcoholic liver disease in the rat. Alcohol: Clin Exp Res 1989;13:15-9.
25. Zeashan H, Amresh G, Singh S, Rao CV. Hepatoprotective activity of Amaranthus spinosus in experimental animals. J Food Chem Toxicol 2008;46:3417-21.

26. Kumar S, Sujatha C, Syamala J, Nagasudha B, Mishra SH. Hepatoprotective activity of extracts from Pergularia daemia forsk against carbon tetrachloride-induced toxicity in rats. Pharmacogn Mag 2007;3:11.

27. Naik SR. Antioxidants and their role in biological functions: an overview. Indian Drugs 2003;40:501-16.

28. Ji LL, Stantman FW, Lardy HA. Antioxidant enzyme systems in rat liver and skeletal muscle. Arch Biochem Biophys 1988;263:150-60.

29. Meister L, Meister A. New aspects of glutathione biochemistry and transport selective alterations of glutathione metabolism. Nutr Rev 1984;42:397-410.

30. Tom A Drixler, Mathys J Vogten, Ewan D Ritchie, Theo JMV. Liver regeneration is an angiogenesis-associated phenomenon. Ann Surg 2002;236:703-12.

31. Losowsky MS, DP Jones, CS Davidson, CS Lieber. Studies of alcoholic hyperlipemia and its mechanism. Am J Med 1963;35:794.

32. Paya M, ML Ferrandiz ML, Sanz MJ, Alcaraz MJ. Effects of phenolic compounds on bromobenzene-mediated hepatotoxicity in mice. Xenobiotica 1993;2:327. 